\title{
Editorial La Serpiente Emplumada, análisis sobre sus aspectos y reflexiones alrededor de la industria cultural en el campo editorial
}

Fecha de recepción: 27 de octubre de 2016

Fecha de aprobación: 12 de noviembre de 2016

Pp. 97-128
Claudia Patricia Rodríguez Zárate

Universidad EAN

crodrigue9.d@universidadean.edu.co

Cómo citar este artículo: Rodríguez, C. P. (2016). Editorial La Serpiente Emplumada, análisis sobre sus aspectos y reflexiones alrededor de la industria cultural en el campo editorial. Comunicación, cultura y política, 7, pp 97-128.

\section{Resumen}

Entendiendo que las Industrias Culturales, se han convertido en un sector estratégico en razón del desarrollo productivo, competitividad, empleo y construcción de consensos que promueven la circulación de información y conocimiento, el sentido de identidad, nuevos modos de entender la economías a partir de un capital más humano y un insumo creativo, el siguiente artículo presenta el estudio de caso de la Editorial Serpiente Emplumada, empresa cultural que nace y se sostiene en el país desde el 2001, como modelo de gestión cultural y ejemplo de industria cultural, perteneciente al sector editorial.

Se pretende, por tanto, no sólo analizar su gestión particular, sino comprenderla dentro de su contexto, en el que, aunque se registra la existencia de políticas culturales de incentivo al consumo del libro, también se enfrentan desafíos como los bajos índices de lectura, la falta de mejores estrategias de financiación por parte del sector público para éste tipo de empresas culturales y los rezagos de analfabetismo.

\section{Palabras clave}

Editorial, industria cultural, empresa cultural, políticas culturales.

\footnotetext{
${ }^{1}$ Investigadora del grupo Política y Sostenibilidad de la Universidad EAN. Becaria del Máster en Gestión de Instituciones y Empresas Culturales Universidad de Barcelona (España). Especialista en Patrimonio y Turismo Sostenible, en el marco de la Cátedra UNESCO de Turismo Cultural, Universidad Nacional Tres de Febrero, Buenos Aires (Argentina). Especialista en Gerencia y Gestión Cultural de la Universidad del Rosario. Filósofa de la Universidad Nacional de Colombia. Docente universitaria. ORCID: http://orcid. org/0000-0001-5525-6124
} 


\title{
Editorial La Serpiente Emplumada, analysis on its own aspects and reflections around the cultural industry in the editorial field
}

\begin{abstract}
Understanding that the Cultural Industries have become a strategic sector due to the productive development, competitiveness, employment and construction of consensus that promote the circulation of information and knowledge, the sense of identity, new ways of understanding economies from a more human capital and a creative input, this article presents the case study of the publishing house Serpiente Emplumada, a cultural company born and maintained in the country since 2001, as a model of cultural management and example of cultural industry, belonging to the editorial sector.

It is therefore intended not only to analyze its particular management, but to understand it within its context, in which, although there are cultural policies to encourage the consumption of books, they also face challenges such as low reading rates, the lack of better financing strategies on the part of the public sector for this type of cultural enterprises, and the lags of illiteracy.
\end{abstract}

\section{Keywords}

Publishing house, cultural industry, cultural enterprise, cultural policies.

\section{Editorial La Serpiente Emplumada, analyse de l'industrie culturelle et réflexion autour du secteur de l'édition}

\section{Résumé}

Les industries colombiennes du secteur culturel se sont converties en un domaine stratégique en raison du développement productif, de la compétitivité, de la construction de consensus participant à la circulation des informations et des connaissances, à la création du sens d'identité et aux nouvelles façons d'appréhender l'économie. Cet article présente l'étude de cas de la maison d'édition le Serpent Emplumé, entreprise culturelle qui naît et fonctionne en Colombie depuis 2001. Cette maison d'édition utilise un modèle de gestion culturelle innovant au sein de l'industrie et du secteur de l'édition.

Nous analyserons dans cet article le mode de gestion de cette entreprise dans un contexte particulier où les politiques culturelles incitent à la consommation de livres mais où les défis tels que le faible taux de lecture, le manque de stratégies de financement du secteur public et l'analphabétisme persistent encore.

\section{Mots clés}

Maison d'édition, l'industrie culturelle, l'entreprise culturelle, les politiques culturelles. 


\section{Editorial La Serpiente Emplumada, análises e reflexões sobre os aspectos da indústria cultural no campo editorial}

\section{Resumo}

Considerando que a indústria cultural se tornou um setor estratégico por causa do desenvolvimento produtivo, da competitividade, da geração de emprego e construção de consensos que promovem a circulação de informação e conhecimento, o senso de identidade, e as novas formas de compreender a economia a partir de um capital humano e input criativo, o seguinte artigo apresenta o estudo de caso da Editora Serpente Emplumada, empresa cultural criada e que se mantém no país desde 2001, como um modelo de gestão cultural e exemplo da indústria cultural, pertencente ao setor editorial.

Pretende-se, portanto, não só analisar a sua gestão particular, mas compreendê-la dentro do seu contexto, no qual, embora existam políticas culturais que incentivam o consumo do livro, também se enfrentam desafios, tais como as baixas taxas de leitura, a falta de melhores estratégias de financiamento por parte do setor público para esse tipo de empresas culturais e o resquício do analfabetismo.

\section{Palavras-chave}

Editora, a indústria cultural, empresarial cultural, politicas culturais. 


\section{Introducción}

T as industrias culturales son un sector empresarial, que, a partir de la década $\smile$ de 1950 al día de hoy, permiten ver que la creatividad sí se constituye en un nuevo motor para la economía, un sustento para el desarrollo y un sostenimiento de nuevas iniciativas empresariales, aun cuando en Colombia el sector editorial puede ver afectado su cadena de valor en relación con otros tipos de industrias culturales, debido al bajo consumo del libro y a la necesidad de desarrollar otros productos de comercialización en el sector, que atiendan más a la cultura digital que circunda hoy al público consumidor. En la actualidad, son más los jóvenes quienes consumen culturalmente (Rey, 2010), en relación con otro tipo de población. Sin embargo, en el sector editorial, optan más por el consumo de libros a través de la red que en formato físico, lo cual obliga a que la industria editorial presente un portafolio de productos más diversificado (Figura 1).

Figura 1. Cadena de valor del libro en la industria editorial.

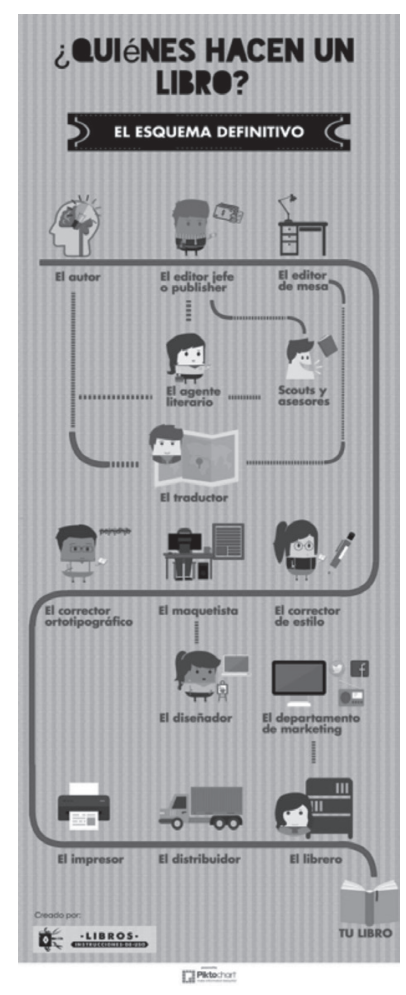

Fuente. www.instruccionesdeuso.es 
En América Latina, el país que más genera empleo gracias a las industrias culturales es Guatemala, con un porcentaje de $7.14 \%$, mientras que Colombia se mantiene en un porcentaje de $2.4 \%$ bastante similar al de Chile, que es de $2.7 \%$ (Figura 2).

Figura 2. Porcentaje de empleo en industrias culturales.

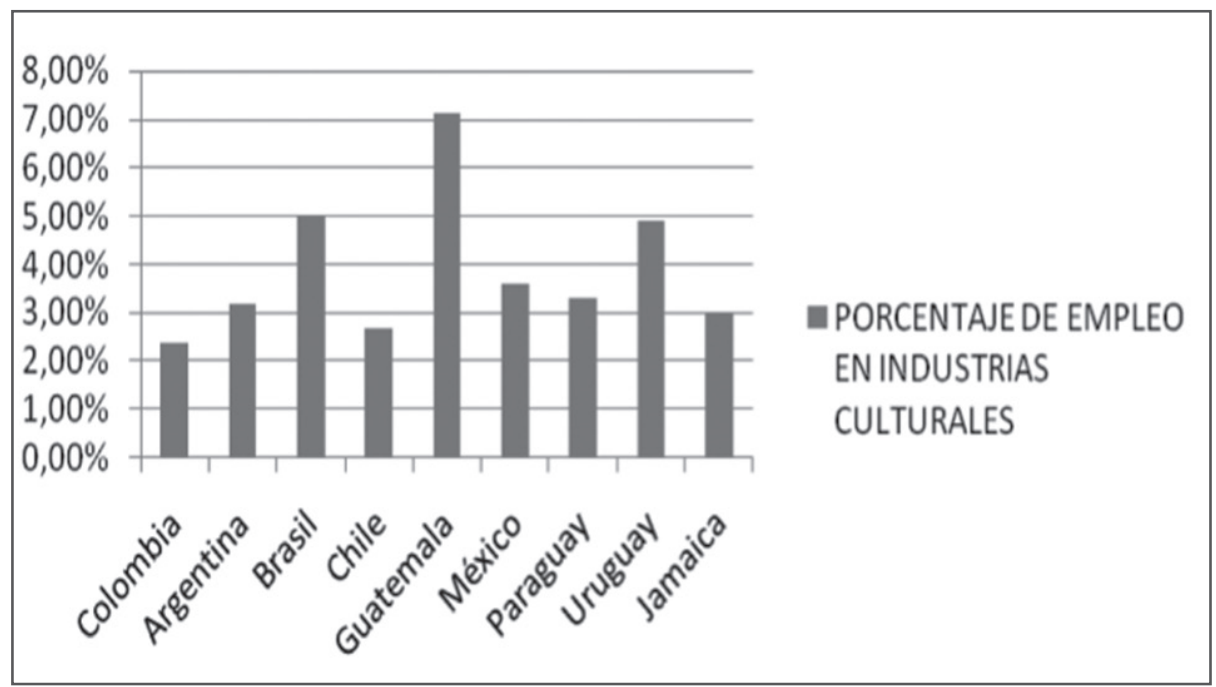

Fuente. Elaboración según Alonso, Bonet, Garzón y Schargorodscky (2010).

Igualmente, cabe mencionar que, según Alonso et al. (2010), los dominios que permiten hablar de industria cultural son los siguientes:

- Patrimonio cultural.

- Patrimonio natural.

- Presentaciones artísticas, entre ellas, artes escénicas, música, festivales y festividades.

- Celebraciones.

- Artes visuales.

- Artesanías.

- Libros y prensa enmarcados dentro del sector de la industria editorial. 
- Medios audiovisuales e interactivos.

- Turismo.

- Deportes y recreación.

\section{La industria editorial}

1 1 comportamiento de la industria editorial alrededor del mundo arroja resultados interesantes para contrastar con el estudio de caso. Los análisis provistos por el Centro Regional para el Fomento del Libro en América Latina y el Caribe (Cerlalc) indican un porcentaje de exportación e importación del libro desde mediados de la década de 1990, con un auge marcado entre 2004 y 2006. En primer lugar, se señala que alrededor del mundo los principales exportadores son el Reino Unido, los Estados Unidos, China y Alemania. De un total de 19 países citados por Cerlalc a fin de ver la participación mundial de los países en relación con la exportación de un bien de consumo cultural como es el libro, Colombia ocupa el puesto 19.

Sin embargo, y partiendo de los análisis efectuados por Cerlalc y tomando como estudio los países de América Latina, Colombia ocupará el segundo lugar con 124018 libros exportados en 2005, y 135315 libros exportados al año siguiente, debajo de México que exportó 147134 libros en 2005 y 152141 libros en 2006, y por encima de Argentina, con una exportación de libros que para 2005 fue de 38604 y 43976 libros exportados al año siguiente, según información brindada por Cerlalc, organismo que cuenta con el auspicio de la Unesco (Rey, 2010, p. 107).

Estos datos son interesantes a la luz de la industria editorial, puesto que indican que los países que encabezan la lista de exportación alrededor del mundo son los que más generan contenido cultural propio, reflejado en un producto de consumo cultural como es el libro, mientras que países como el nuestro carecen de esa producción de contenidos, lo cual puede conducir a pensar que se debe a problemas como analfabetismo, falta de apropiación, desconocimiento de la identidad cultural y bajos índices de lectura. 
El DANE (2008) presentó un estudio relacionado con los hábitos de consumo cultural, los cuales se han incrementado en Colombia desde 2000, y realza que el mayor público consumidor de bienes de tipo cultural son los niños y los jóvenes. Dentro de este, es pertinente mencionar la siguiente información relacionada con el sector de la industria editorial. Tomando como muestra un universo compuesto de niños entre los 5 y 11 años, los porcentajes muestran que $54.88 \%$ ha leído libros en el último año, $74.26 \%$ no ha leído revistas, $82.85 \%$ no ha leído periódicos. Se concluye, además, que estos últimos son preferidos por una población adulta y de tercera edad, mientras que los niños prefieren leer los libros. Por su parte, el otro público consumidor fuerte de productos culturales, esto es, los jóvenes, opta por leer revistas, periódicos y libros que encuentren en formato digital y a través de internet, mas no en formato físico.

Del mismo modo, es interesante apreciar también a la luz de la información provista por Cerlalc que, en América Latina, Colombia se sitúa por encima de un país como Argentina, que presenta más hábitos de lectura. En temas de exportación, Argentina se coloca por debajo de nuestro país, con unas cifras de exportación de 38604 para 2005 y 43976 para 2006 respectivamente, lo cual indica que si bien Colombia, cuenta con bajos índices de lectura que se pueden contrastar con posibles causas como las anteriormente propuestas, si cuenta con estrategias de exportación.

Por su parte, el Observatorio de Cultura y Economía (2016), iniciativa del Grupo de Emprendimiento del Ministerio de Cultura, el cual busca, a partir de su creación en 2011, generar, diseñar y difundir información e instrumentos de análisis a fin de que actores interesados en sectores relacionados con la cultura, como la economía, el emprendimiento y la industria, puedan tener un mejor conocimiento de estos sectores y mejorar su competitividad, proporciona gracias a sus estudios cifras por tener en cuenta en relación con la industria editorial. De este modo, el Observatorio muestra que, mientras el número de títulos producidos denota una diversidad de oferta para el lector, la cantidad de ejemplares indica su fortaleza tanto en el mercado editorial como en el público lector. En Colombia, para 2012, se produjeron aproximadamente 30 millones de ejemplares comercializables, según la Cámara Colombiana del Libro (2015), al tiempo que en México se presentó una producción de 145 millones de ejemplares para el año siguiente, de los cuales 102 de estos fueron adquiridos por el mercado y los 43 millones restantes por el Gobierno. El Observatorio, además, muestra la 
imperiosa necesidad de generar más estudios, pues lamentablemente, teniendo en cuenta el contexto iberoamericano, la industria editorial carece de estos, a excepción de países como Colombia, México y Brasil, en los que se procura contar con investigaciones que presenten cifras o indicadores. En este sentido, el International Standard Book Number (ISBN) se convierte, entonces, en la mejor herramienta para tener una mirada de la producción editorial, que, aun cuando no puede englobar toda la producción editorial en tanto no todos los libros y publicaciones son registrados, sí permite tener otra mirada. Según el Observatorio (2016), en relación con los títulos registrados entre 2002 y 2012 en el ISBN, se relacionan a continuación las infografías elaboradas por este a partir de información provista por Cerlalc.

Figura 3. Títulos registrados en el ISBN (2002-2012).

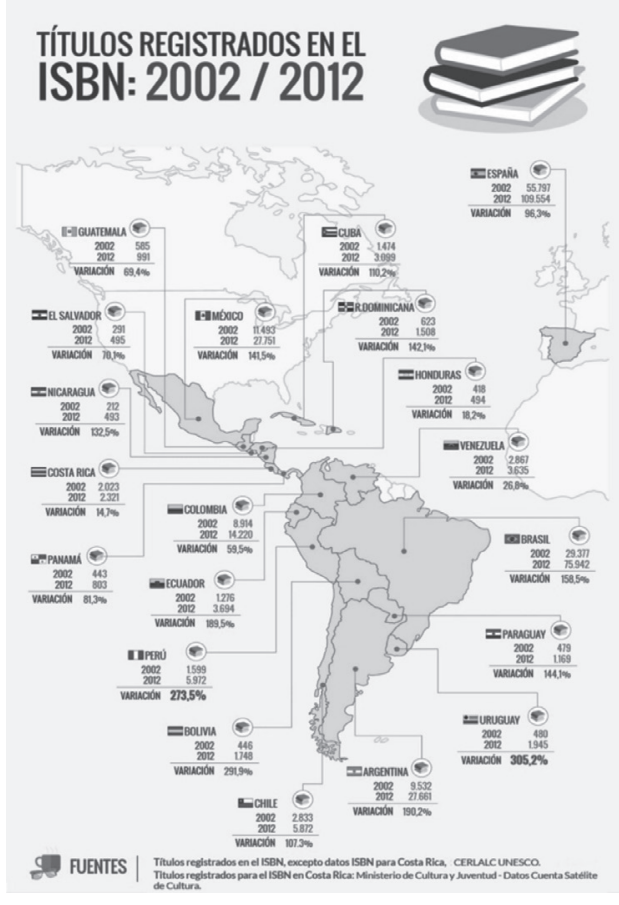

Fuente. Infografía producción de libros y lectura en Iberoamérica (Observatorio cultura y economía, 2016). 
Como muestra la figura 3, el crecimiento en materia de producción en general para todos los países fue superior a $100 \%$, lo cual indica que la industria editorial presenta mayor profesionalización, mayor cantidad de números de ISBN para las publicaciones y mayor asistencia a eventos internacionales, como las ferias internacionales del libro para divulgación, promoción, distribución y comercialización de libros y derechos de autor. Además, permite apreciar que Argentina, Brasil y México son los países más fuertes para la industria editorial, señalando porcentajes en relación con la edición de libros de $190.2 \%, 158.5 \%$ y $141.5 \%$, respectivamente.

Figura 4. Hábitos de consumo de lectura.

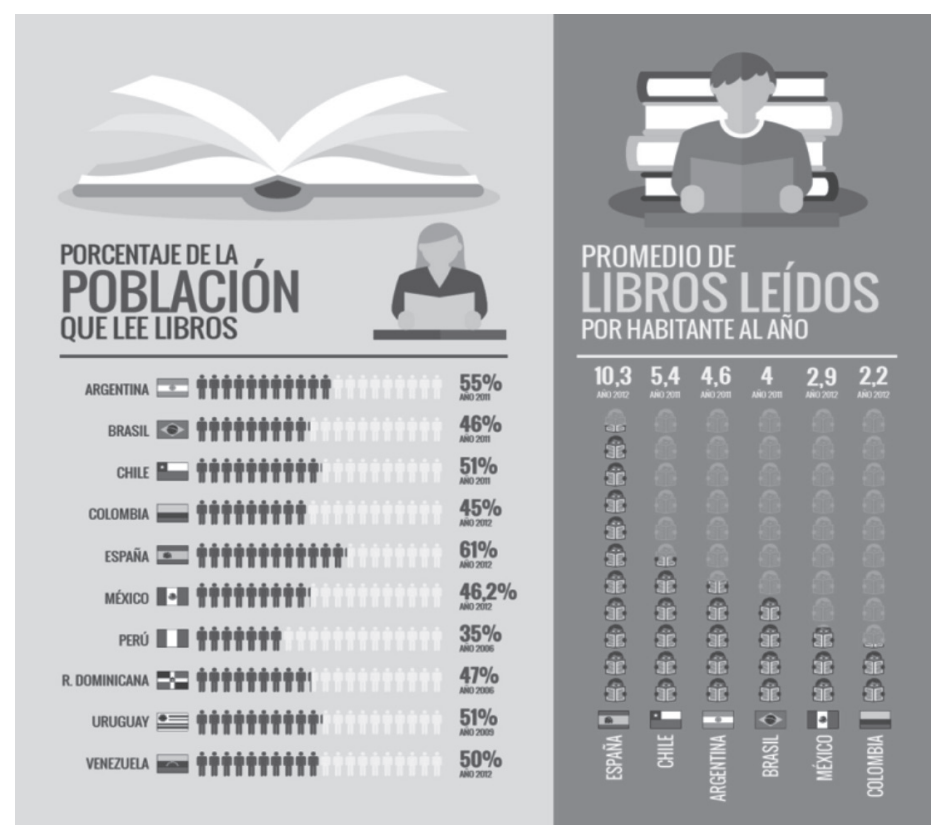

Fuente. Infografía producción de libros y lectura en Iberoamérica (Observatorio cultura y economía, 2016).

En cuanto a los hábitos de lectura para 2012, se puede afirmar que los países que presentan mayor porcentaje de población lectora son, en orden de mayor a menor, España (61 \%), Argentina (55 \%), Chile (51\%) y Uruguay (51 \%). El país con menor porcentaje de población lectora es Perú con $31 \%$; y Colombia, con $45 \%$. En cuanto al número de libros leídos por lector al año, $10.3 \%$ es la cifra de libros leídos en España por habitante al año, que ubica a este país europeo en primer lugar; y $2.2 \%$ es la cifra de libros leídos en Colombia por 
habitante al año, que sitúa a nuestro país en el último puesto. Esta información compleja de analizar si se tiene en cuenta que en Colombia tiene lugar una de las ferias del libro más importantes del mundo, que se constituye en el evento de promoción de la lectura y la industria editorial más importante del país. La Feria Internacional del Libro de Bogotá (Filbo), que desde sus inicios en 1988 comenzó a perfilarse como una de las más importantes en América Latina, ha trabajado estrategias de gestión cultural para potencializar la industria editorial, como La noche de los libros, donde se permite libre acceso desde las seis de la tarde hasta la media noche. Esta iniciativa ha llevado a un incremento en el número de visitantes aproximadamente de $25 \%$.

Asimismo, como segunda estrategia de gestión cultural, se realizó la Rueda de negocios internacional en compañía de Proexport, evento que ha convocado aproximadamente 220 editoriales, con una expectativa de negocios cercana a los USD 20428069 millones de dólares y una participación de 120 compradores del mundo. Como dato por destacar, se señaló que el mayor número de negocios en torno del producto de consumo cultural estrella para este suceso como lo fue el libro, se cerró con México que indicó, precisamente, que $45 \%$ de las ventas se efectuó en países de Centroamérica.

Ahora bien, desde un punto de vista legal y para el caso de Colombia, es importante mencionar que existe una normativa referente al tema. El documento Conpes 3659 de 2010, Política nacional para la promoción de las industrias culturales en Colombia, comprende la necesidad que tiene el Estado de proporcionar un mayor número de oportunidades para las micro, pequeñas y medianas empresas culturales, con el objetivo de aprovechar el potencial competitivo de las industrias culturales, aumentar su participación en la generación del ingreso y el empleo nacionales y alcanzar elevados niveles de productividad.

Así es como con esta política dispondrá, además de los objetivos antiores, de líneas estratégicas orientadas a superar los obstáculos que existen en la circulación de los productos de estas industrias y ampliar el acceso al financiamiento. El Conpes 3659, junto con la Conferencia de las Naciones Unidas sobre Comercio y Desarrollo, presentan una participación de estas en el PIB nacional, en alzada gradualmente desde 2000 hasta 2007 , y un porcentaje por destacar de $25.7 \%$ en cuanto a temas de exportación derivados del sector editorial. 


\section{La historia de la Editorial La Serpiente Emplumada}

T a Editorial La Serpiente Emplumada es una empresa cultural que nace Jy se sostiene en el país desde 2001 como modelo de gestión cultural y ejemplo de industria cultural. Su objeto social responde a la edición, impresión, comercialización, promoción y representación de libros, así como a la venta de derechos de autor dentro del sector editorial.

Esta editorial fue inscrita por primera vez el 25 de mayo de 2001 como empresa unipersonal y posteriormente paso a ser sociedad limitada, previa inscripción ante la Cámara de Comercio de Bogotá el 25 de agosto de 2006.

Surgió como un proyecto cultural a partir del nacimiento de la obra Un vestido rojo para bailar boleros escrito en 1988 por Carmen Cecilia Suárez Mantilla, fundadora y gerente de la editorial, quien en aquel entonces, luego de descubrir la exitosa receptividad que recibió su obra en el mercado (diez ediciones en español y una edición bilingüe), se une en primera instancia con Esperanza Dorado su principal aliada y líder para la editorial en temas de distribución.

En 1988, se servirán de Pijao editores para el tema de distribución y posteriormente de Arango editores en 1989, mientras es constituida la Editorial La Serpiente Emplumada como empresa unipersonal en 2001. La gerente tomó dicha decisión, pues, luego de financiar su iniciativa cultural, fue consciente de la dificultad que representa crear una empresa "sola" especialmente desde un punto de vista financiero, por lo cual decidió invitar a socios a participar.

Hoy la editorial constituida como sociedad limitada desde 2006 está conformada por Carmen Cecilia como accionista principal, junto con nueve socios más. Las estrategias de la editorial guardan correspondencia con su objeto social, como edición, impresión, distribución, comercialización, promoción y representación de libros y material de interés cultural, científico, literario y periodístico, principalmente. 
La editorial, cuyo nombre proviene de la mitología maya, se constituye en una red de escritores colombianos para ayudar a otros escritores latinoamericanos a publicar, distribuir y difundir su obra. Cuenta con presencia internacional, pues se ha presentado en la ferias de Fráncfort (Alemania), Guadalajara (México) y Boloña (Italia) el año pasado. Lo anterior permite inferir que la editorial busca con sus estrategias apuntar al mercado nacional e internacional. Por otro lado, según la gerente, el lema de esta editorial independiente es hacer las cosas bien y ejercer un liderazgo planificador y participativo.

\section{Estructura y funcionamiento de la Editorial La Serpiente Emplumada}

T sta editorial, que surge en 2001 ,y se constituye como sociedad limitada desde promoción y representación de todo tipo de libros y material de interés cultural.

Las áreas que comprometen sus libros pertenecen a las categorías de literatura, ciencia, periodismo y academia, contenidas a su vez en las siguientes colecciones: Colección Vestido Rojo, Colección Coordenada Cero, Colección Pulgarcita, Colección de los Sabios y Colección Opera Prima.

En cuanto a su organigrama principal, la editorial está compuesta por la gerente y la junta directiva compuesta por sus socios. Las funciones de la gerencia son las siguientes:

- Usar el nombre de la sociedad.

- Designar los empleados de la compañía, que por estatutos no sean nombrados por la junta como socios.

- Precisarle a los empleados de la compañía como habrán de vincularse.

- Presentar informe de su gestión a la terminación del ejercicio contable, en reuniones ordinarias de la junta de socios.

- Convocar reuniones ordinarias y extraordinarias a la junta de socios. 


\section{Análsis por componentes}

T a investigación en relación con laEditorial La Serpiente Emplumada se sirvió $\smile$ de un instrumento de análisis como es el modelo de modernización para la gestión de las organizaciones (MMGO), texto constituido en una propuesta para las empresas que buscan forjar su futuro a partir de su conocimiento interno.

El MMGO se diseñó modularmente acorde con los estadios que una empresa debe superar para modernizarse y hacerse más competitiva en cuanto a su gestión. Igualmente, la investigación parte de una pregunta articuladora como “¿Qué características ha presentado la Editorial La Serpiente Emplumada como modelo de gestión y como ejemplo de industria cultural y de qué manera ha desarrollado el trabajo en red?".

\section{Direccionamiento estratégico}

D e acuerdo con el MMGO, se entiende por direccionamiento estratégico un sistema que agrega valor a las operaciones está acompañado de una estructura organizacional adecuada y un sistema de valores de todos los miembros de la organización, alineando la estrategia y el sistema de finalidades. En el direccionamiento estratégico de una organización, es de suma importancia para ella contar con una planeación orientada a la gestión, el desempeño y el control como una batería de indicadores para monitorear los objetivos planteados, de tal manera que se dé aprendizaje organizacional y conocimiento. (tabla 1 y figura 5). 
Tabla 1. Resumen de factores.

\begin{tabular}{|l|l|}
\hline Principios de planeación & 12.50 \\
\hline Sistema de finalidades (misión, visión y objetivos) & 25.00 \\
\hline Valores corporativos & 29.17 \\
\hline Estrategias & 31.25 \\
\hline
\end{tabular}

Estadio 1. Calificación componente: $24.48^{2}$.

Fuente. Elaboración propia.

Figura 5. Direccionamiento estratégico de la editorial.

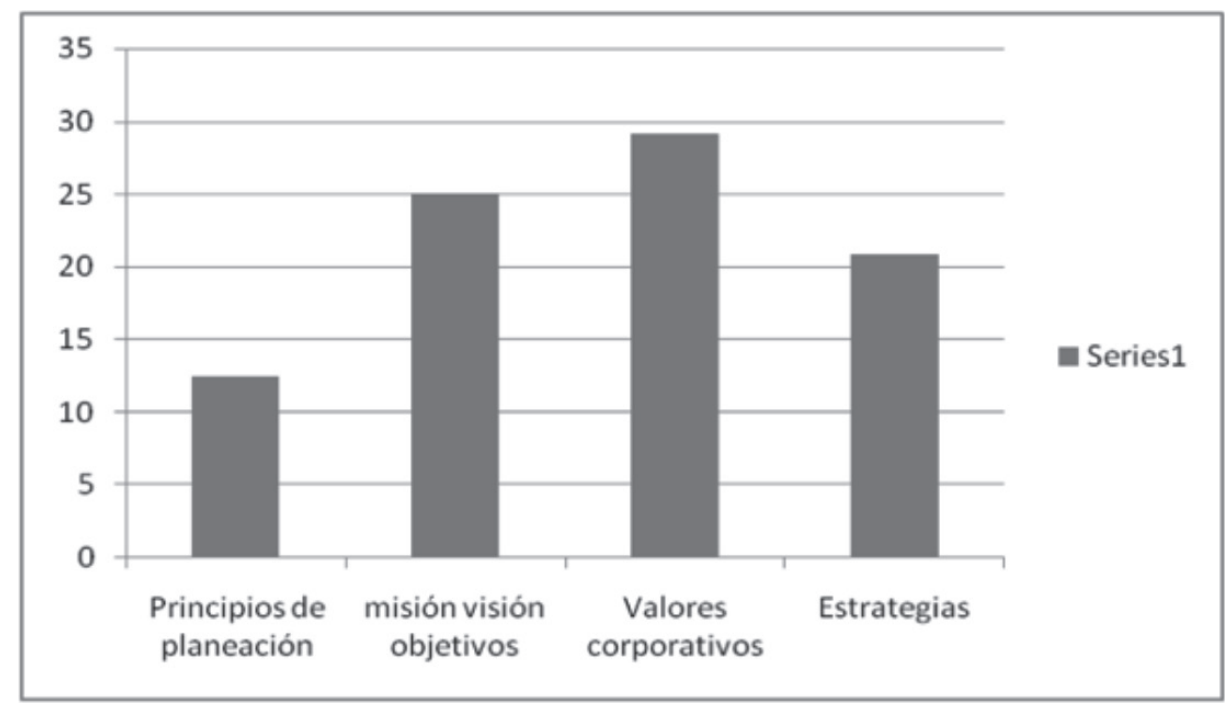

Fuente. Elaboración propia.

2 La información consignada las tablas es el resultado de la aplicación de las matrices pertenecientes al MMGO Modelo de Modernización para la Gestión de Organizaciones, diseñado en relación con los estadios que una empresa tradicional debe superar para modernizarse 


\subsection{Análisis situacional}

\subsubsection{Potencialidades}

La gerente posee un lema que destacó en entrevista y que transmite a su equipo de trabajo, que es hacer las cosas bien. Ella viene de liderar un colegio, de dirigir asuntos de finca raíz, así como curso una maestría en investigación de la Universidad Sergio Arboleda. Comprende bien lo que significa la palabra organización, además de ser una mujer autónoma e independiente.

\subsubsection{Problemas}

La Editorial La Serpiente Emplumada cuenta con un buen liderazgo en cabeza de su gerente y fundadora Carmen Cecilia Suárez, sin embargo, carece de mayor delegación. Para la gerente y escritora, la editorial es una empresa y un proyecto cultural que, si bien debe ser visible, palpable y real desde un punto de vista económico, funcionó con otro criterio cuando nació. Es su sueño. Si bien la gerencia está en disposición de atribuir funciones y cuenta con una estructura organizacional, la mayo parte del funcionamiento de la empresa recae en cabeza de ella y de la encargada de distribución Esperanza Dorado, lo que hace más difícil depurar los datos para la investigación, y conduce a pensar que de faltar la gerente o el equipo que conforman las dos, muy seguramente la editorial llegaría a su fin, a pesar de ser una sociedad limitada que cuenta con el capital de los demás socios. Ellos, por su parte, parecieran estar más comprometidos con la editorial por su amor a la cultura literaria, sentimiento que comparten con la gerente, que por el deseo de apropiar, conocer y liderar un modelo de negocio.

\subsubsection{Ruta de mejoramiento}

La gerencia debe delegar de manera continua, pues, si bien y en algunos casos ha hecho aprovechamiento de las capacidades de sus socios para involucrarlos en otras áreas de la empresa, permitiéndoles desempeñar otros roles, no hacerlo con cierta continuidad resta que otros miembros de la editorial perfeccionen sus capacidades y, por ende, es la gerencia la que termina desempeñando varios roles a la vez que refleja una estructura organizativa piramidal. 


\section{Gestión de mercadeo}

e acuerdo con el MMGO, en este apartado, y a partir de la aplicación de la matriz de mercadeo, se exploran las actividades de gestión de mercados y comercialización realizadas por la empresa. En la calificación que se obtiene, son importantes la implantación de procesos formales de estudio y análisis de los mercados y segmentos, el reconocimiento de un producto con sus atributos de mercado, la promoción de los productos en los mercados objetivos, el análisis formal de los precios, la organización de sistema de distribución y la realimentación que se obtenga de los clientes y distribuidores (tabla 2 y figura 6 ).

Tabla 2. Resumen de factores. Estadio 2. Calificación componente: 34.44.

\begin{tabular}{|l|c|}
\hline Orientación de la organización hacia el mercado & 25.00 \\
\hline Planeación y control del mercadeo & 33.33 \\
\hline Investigación de mercados & 8.33 \\
\hline Comportamiento del actor social, cliente, usuario y consumidor y segmentación & 33.33 \\
\hline Estrategia de producto o servicio & 33.33 \\
\hline Estrategia de precios o tarifas & 19.44 \\
\hline Estructura y estrategia de distribución (si aplica diligéncielo) & 79.17 \\
\hline Estrategias de ventas & 25.00 \\
\hline Estrategia de comunicación & 66.67 \\
\hline Servicio al actor social, cliente, usuario y consumidor & 20.83 \\
\hline
\end{tabular}

Fuente. Elaboración propia.

\subsection{Análisis situacional}

\subsubsection{Potencialidades}

La figura 6 permite analizar que cuenta con unas estrategias de comunicación y distribución claramente definidas por parte de Esperanza Dorado, quien conoce con propiedad la organización, puesto que está desde sus inicios acompañando a Carmen Cecilia Suárez en el desarrollo de la idea y en la sostenibilidad de la organización. 
Figura 6. Estrategia de mercadeo de la editorial.

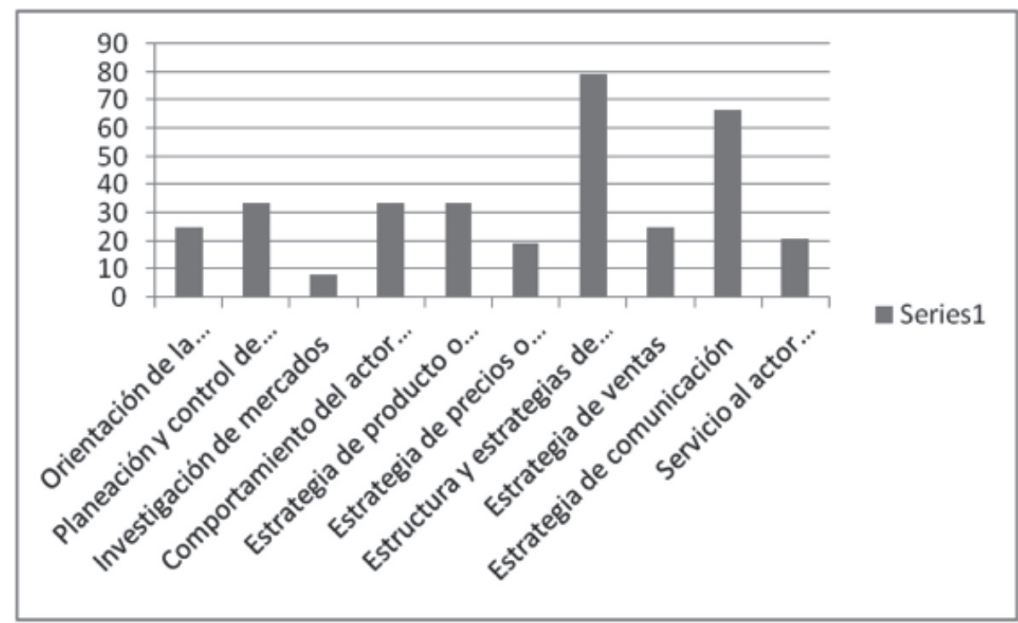

Fuente. Elaboración propia.

En primer lugar, la editorial edita, comercializa y distribuye derechos de autor en el ámbito nacional e internacional; en segundo lugar, comercializa títulos de otras editoriales, y en tercer lugar, convoca a nuevos escritores colombianos y latinoamericanos a participar a través de sus libros, siempre y cuando se ajusten a las políticas internas de la editorial y a la aprobación de todos sus miembros bajo la premisa de que las obras correspondan con las temáticas planteadas por sus colecciones, y sus autores tengan una trayectoria académica y cultural.

Posee cinco colecciones: Vestido Rojo, en la que se abordan los géneros literarios de novela, cuento y ensayo literario, y dentro de la cual se destacan veintitrés títulos. Ópera Prima que busca promover la obra de jóvenes escritores y que hoy destaca seis títulos. Laura Victoria, colección dedicada a la poesía con ocho títulos. Pulgarcita cuya temática es literatura para niños y en la que se destacan cuatro títulos. Coordenada Cero que aborda siete libros académicos. Y Los Sabios, un conglomerado de textos de la cultura maya y de otras culturas antiguas, con dos títulos, respectivamente.

En cuanto a la comercialización y distribución de derechos de autor, cabe mencionar que poseen un catálogo en físico con los siguientes escritores que son los de mayor renombre para la editorial: 
- Carmen Cecilia Suárez

- Agustín Morales Rivera

- Benhur Sánchez Suárez

- Mauricio Botero Montoya

- Gladys Villamizar

- Andrés Elías Flórez

- Campo Ricardo Burgos

- Gloria Díaz Salom

- María del Carmen Parias López

- Clemencia Montalvo Villegas

- Asindi Rex We

Además, está el catálogo virtual, en el que comercializan con otros escritores, dentro de los cuales se pueden mencionar los siguientes:

- Mauricio Botero Montoya

- Fernando Soto Aparicio

- Adelayda Fernández Ochoa

- Jairo Nieto

- Francisco José Restrepo

- Jesús Emilio García

- Agustín Castillo

- Luis Fayad

- Sebastián Chalela

- Fernando Denis

- Carolina Mayorga

- Lilia Gutiérrez Riveros

- Victoria de Hoyos

- Loretta Van Iterson (Holanda)

Es importante también destacar que su catálogo en físico se encuentra en español e inglés y el digital está traducido al alemán. Ello se hace con el fin de apuntar a mayor número de mercados y aprovechando la presencia que la editorial ha tenido en ferias del libro celebradas en Guadalajara (México), Bolonia (Italia) y Fráncfort (Alemania). 


\subsubsection{Problemas}

La editorial debe brindar mayor capacitación a sus empleados en temas de investigación de mercados especialmente, en los roles que compromete su cadena de valor para llegar a la comercialización del producto, pues si bien ya está incursionando en el mercado digital y conquistando nuevos nichos, dicho conocimiento y dichas estrategias, son de dominio de pocos miembros de la empresa. En algunos casos en temas de actualización de catálogo y oferta por la web, se acude a personal de la Universidad Sergio Arboleda, espacio con el cual la gerencia sostiene una buena relación.

\subsubsection{Ruta de mejoramiento}

Se sugiere brindar mayor capacitación y actualización a los socios y empleados de la editorial, en las nuevas tendencias del mercado en temas de comercialización de libros y derechos de autor.

\section{Logística}

e acuerdo con el MMGO, en este aspecto, se evalúa la logística de la empresa, la planeación y la proyección de sus recursos productivos necesarios para satisfacer a los clientes y las relaciones que se pueden mejorar con ellos y los proveedores con el uso de la logística.

Tabla 3. Resumen de factores Estadio 1. Calificación del componente: 18.98.

\begin{tabular}{|l|r|}
\hline Planeación logística & 25.00 \\
\hline Relaciones internas y externas & 33.33 \\
\hline Administración de materiales & 8.33 \\
\hline Organización & 25.00 \\
\hline Control logístico & 16.67 \\
\hline Gerencia de logística & 29.17 \\
\hline Competencia logística & 8.33 \\
\hline Indicadores logísticos & 16.67 \\
\hline Sistema de información & 8.33 \\
\hline
\end{tabular}

Fuente. Elaboración propia. 
Figura 7. Logística de la editorial.

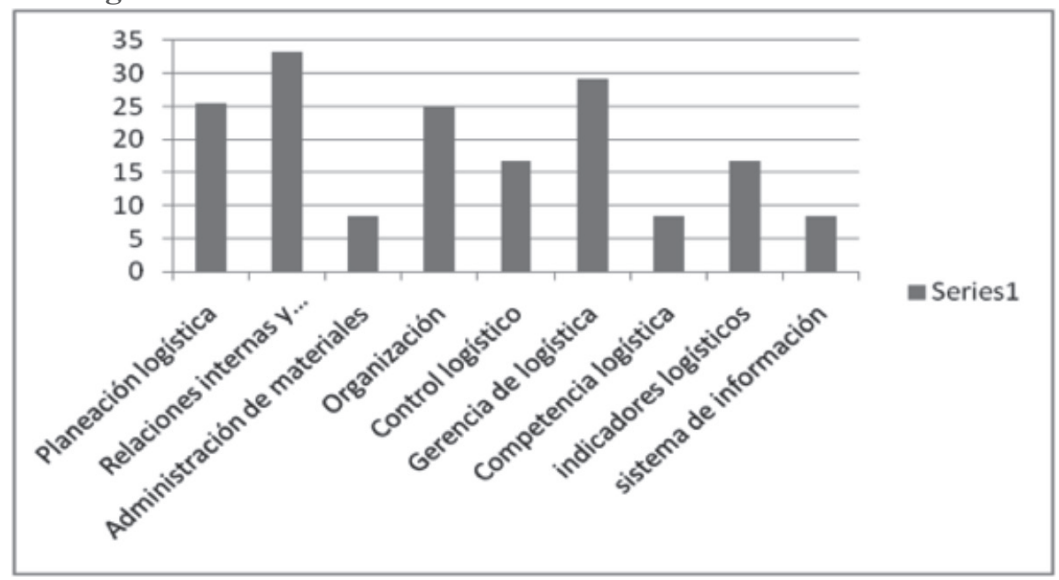

Fuente. Elaboración propia.

\subsection{Análisis situacional}

\subsubsection{Potencialidades}

La editorial cuenta con una librería que fue abierta al público el 25 de septiembre de 2011, ubicada en la calle 10 \# 3-17, en horario de atención de lunes a sábado de 2:00 a 7:00 p. m. Cuenta con oferta de su sello editorial y de otras empresas editoriales para un total de 95 títulos. Además, con servicio de cafetería, alquiler de juegos de mesa y espacio para la organización de eventos culturales, dentro de los que cuentan conciertos musicales, lecturas de poesía y exhibiciones itinerantes de artes plásticas con especial énfasis en pintura.

Los títulos que se comercializan oscilan entre los $\$ 20000$ y $\$ 60000$, que también se pueden pagar en dólares o euros.

Por otra parte, dispone de una buena planeación logística, debido a que cuenta con un buen equipamiento como es el espacio donde opera la editorial, una casa grande ubicada en la localidad de la Candelaria, sitio geográfico que conecta bastante bien con los imaginarios de cultura, creación y, por supuesto, literatura. 
La editorial opera en una casa ubicada frente a la Fundación Gilberto Álzate Avendaño, hecho que facilita la posible consecución de alianzas estratégicas entre las dos partes en temas de publicidad y gestión de eventos culturales. Además, la casa contiene una librería que se traduce en un grato espacio para el consumo de la cultura, por lo cual está generando una dinámica en el sector alrededor del consumo y como consecuencia también, la necesidad de diseñar una programación cultural.

\subsubsection{Problemas}

Al contar con un pasante universitario como encargado de la librería, corre el riesgo de perder posicionamiento en el mercado.

\subsubsection{Ruta de mejoramiento}

Contratación de un gestor cultural para apoyar el manejo de la librería, de modo que esta se posicione en el mercado, y se le atribuya principalmente el rol de programador cultural, teniendo en cuenta, además, que el equipamiento, la vecindad y la ubicación geográfica de esta en la localidad de la Candelaria le proporcionan un excelente plus en el mercado del libro.

\section{Comercio exterior, importaciones y exportaciones}

$7 \mathrm{n}$ este apartado, de acuerdo con el MMGO, se evalúa la existencia de una Cestrategia de exportaciones definida y explicita, el insumo de información sobre los mercados externos, la existencia de productos y servicios exportables y cómo la empresa mide y recibe realimentación de esos mercados para la toma de decisiones interna (tabla 4 y figura 8 ). 
Tabla 4. Resumen de factores. Estadio 2. Calificación del componente: 33.33.

\begin{tabular}{|l|l|}
\hline Preparación para mercados externos & 45.83 \\
\hline Talento humano orientado al exterior & 52.78 \\
\hline Estrategia de la empresa para exportar & 47.22 \\
\hline Conocimiento y análisis competencia internacional & 20.83 \\
\hline Diferenciación del producto o servicio & 16.67 \\
\hline Flujos de información y control & 16.67 \\
\hline
\end{tabular}

Fuente. Elaboración propia.

Figura 8. Comercio exterior y exportaciones de la editorial.

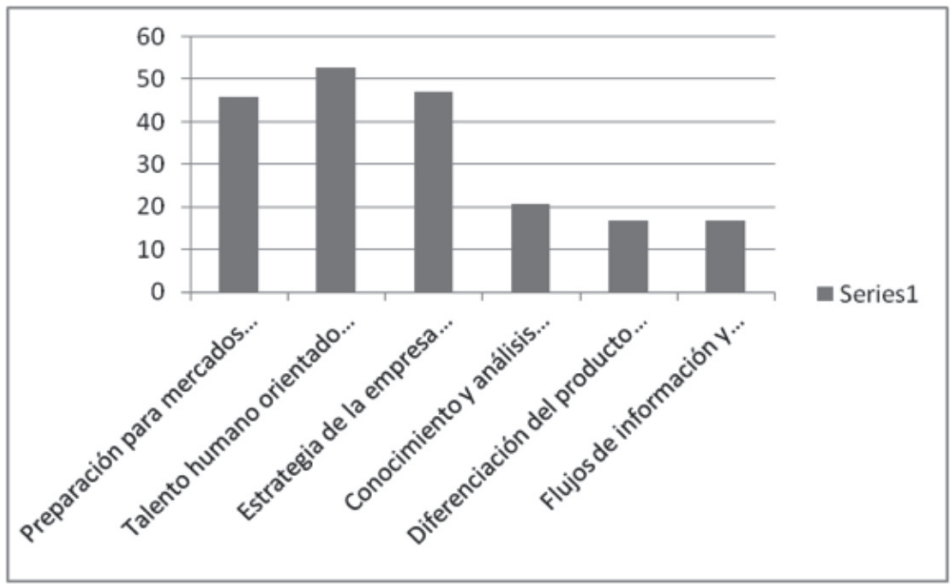

Fuente. Elaboración propia.

\subsection{Análisis situacional: exportaciones}

\subsubsection{Potencialidades}

La editorial comercializa libros y derechos de autor en otros países. Para ello, se sirve de dos estrategias: 1) la página web donde tienen un apartado de compras que permite la venta de libros a través de Amazon y 2) la visita a ferias del libro en el exterior. Así es como la editorial ha sido invitada a las ferias de Fráncfort en Alemania, donde fue seleccionada como empresa independiente por dos años seguidos y en la que se vendieron derechos de autor al alemán. Además 
de Guadalajara donde tuvieron dos estands, uno de Colombia comandado por Esperanza Dorado y el otro el de derechos de autor comandado por la gerente Carmen Cecilia Suárez. Finalmente, se destaca la presencia de la asesora de comercio exterior Catherine Rojas en la Feria Internacional del Libro Infantil y Juvenil Bolonia en el 2011.

En este apartado, cabe mencionar que la gerente es quien ha participado la mayoría de las ocasiones en estos eventos, sin embargo, encontró que dentro de su recurso humano contó con una profesional formada en relaciones exteriores de manera tal que le brindó la oportunidad de asistir a dos ferias en 2011 a Guadalajara y Bolonia, con el ánimo de que ella misma pudiese establecer nuevas relaciones comerciales con el exterior y efectuar venta de derechos de autor. La profesional, quien se desempeña como asesora de comercio exterior para la editorial, contó con financiación para su viaje y cobró por comisión respecto de los derechos de autor que pudiese vender allí.

Proexport apoya además con pasajes, presencia en ventas internacionales; por ejemplo, para la Feria del Libro de San Salvador cubrieron viáticos como para las ferias de Fráncfort y Guadalajara, además dan algunos apoyos para la web.

La editorial sí está sumamente interesada en penetrar en el mercado exterior, entendiendo que los hábitos de consumo de libros en Colombia son mucho más bajos que en otros países, puesto que procura operar en red, de modo que apoye escritores colombianos y latinoamericanos y finalmente porque es su deseo comenzar a comercializar con los derechos de autor de sus escritores en otros países, con el propósito de generar otros nichos de mercado. Esta comprensión es apropiada principalmente desde la gerencia, confirmando lo dicho, gracias a la presencia constante de su gerente en ferias del libro en otros países y, además, dado que en la medida en que se ha visto la penetración de los productos de la editorial en otros mercados extranjeros, la gerencia ha considerado la necesidad de delegar y apoyarse en otro elemento como lo es su asesora de relaciones exteriores, quien cuenta con la formación académica en este ámbito. 


\section{Cultura organizacional de la empresa}

e acuerdo con el MMGO, con este apartado se busca que esta variable examine el alcance y la profundidad con que se desarrolla, involucra y apoya a las personas para que participen en el mejoramiento de la calidad de vida. Determina si se fomenta su desarrollo para hacerlas autónomas y creativas, con capacidad de colaborar y comprometerse activamente con el mejoramiento de la empresa con sus procesos, productos y servicios. También se estudian los esfuerzos de la pyme para construir y mantener un ambiente que propicie la participación real, el trabajo en equipo y el respeto por las personas (tabla 5 y figura 9).

Tabla 5. Resumen de factores. Estadio 2. Calificación del componente: 42.19.

\begin{tabular}{|l|r|}
\hline Liderazgo & 56.25 \\
\hline Participación y compromiso & 37.50 \\
\hline Desarrollo y reconocimiento & 29.17 \\
\hline Creación de un entorno vital para todos los trabajadores & 45.83 \\
\hline
\end{tabular}

Fuente. Elaboración propia.

Figura 9. Cultura organizacional de la editorial.

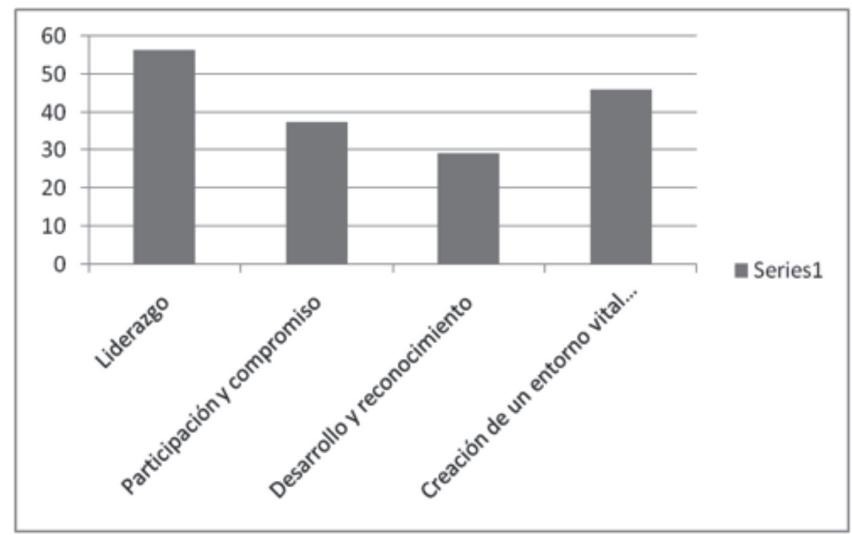

Fuente. Elaboración propia. 


\subsection{Análisis situacional}

La accionista mayoritaria y representante legal es la gerente Carmen Cecilia Suárez, quien tiene las siguientes funciones:

- Usar el nombre de la sociedad.

- Designar el secretario de la sociedad que será también el de la junta de socios y fijarle sus funciones y remuneración.

- Designar los empleados de la compañía que por ley o por los estatutos establecidos ante la Cámara de Comercio en el momento de la inscripción de la editorial no sean nombrados por la junta como socios.

- Precisarles a empleados de la compañía cómo habrán de vincularse.

- Presentar el informe de su gestión a la terminación del ejercicio contable en las reuniones ordinarias de la junta de socios.

- Presentar el balance respectivo junto con el proyecto de distribución de utilidades.

- Convocar a reuniones ordinarias y extraordinarias de la junta de socios.

- Constituir apoderados judiciales y extrajudiciales para defender los intereses de la sociedad cuando lo considere necesario.

- Las funciones que deba desarrollar para defender sus intereses y los de sus socios.

El equipo de la editorial está conformado por la gerencia, una coordinadora administrativa, una contadora, una persona encargada de manejar el área digital junto con contratación, teléfono y correspondencia, un mensajero que es pagado mitad por la gerente y mitad por la editorial; este, además, apoya el archivo. Se cuenta eventualmente con practicantes de colegio y universidad $\mathrm{y}$ una asistente personal.

La editorial opera con esquemas de trabajo flexible, es decir, por más tiempo que se emplee en la editorial, es más el dinero que se gana. Sin embargo, se busca que sus miembros desarrollen otras actividades paralelas que les generan ingresos adicionales. A medida que la empresa vaya creciendo, se aumentará el número de horas laboradas por cada uno de los miembros y con ello el salario. 
La editorial trabaja bajo sistema de referidos, así como estudiantes de la Universidad Sergio Arboleda en calidad de pasantes y de colegios. Los correctores de estilo son escritores de la editorial.

\subsection{Potencialidades}

La empresa cuenta con una cultura organizacional, con funciones claras y apropiadas por sus socios y escritores, quienes llevan bastante tiempo vinculados a esta como por parte de sus empleados.

\subsection{Problemas}

La cultura organizacional se conoce, se apropia, sin embargo, es necesario comprender el liderazgo de la empresa desde la gerencia, con la salvedad que esta comience a delegar un poco más.

\section{Gestión financiera}

D e acuerdo con el MMGO, en este apartado se buscan analizar las variables de inversión, financiación y rentabilidad como variables fundamentales y sustenta la observación en los elementos y medios desarrollados por la empresa, los procesos definidos y finalmente la información producida, su calidad y sus niveles de divulgación.

\subsection{Análisis situacional}

Respecto de la gestión financiera, la editorial usa los siguientes instrumentos: el análisis contable que se efectúa una vez al año por parte de la gerente. Así es como ella y la contadora aprecian en qué se ha gastado el dinero, asimismo de dónde reciben proyección, y revisan el plan estratégico diseñado y los resultados dados; evaluación editorial; evaluación cualitativa; resultado de los procesos; 
evaluación financiera en la que ella se reúne en primera instancia con Esperanza Dorado quien efectúa las labores de distribución y posteriormente con los demás miembros y socios de la editorial.

El dinero que ingresa a la editorial se queda en el mismo sector cultural. En librerías, otro va para los socios lectores que ganan por cada libro que lean y que se publique. Otros ingresos van para la distribución y otros para el taller de edición. Por otro lado, están las regalías para los escritores.

Los ingresos también se dan por compras públicas donde se citan muy buenos clientes como en su momento lo fue la Biblioteca Luis Ángel Arango y también la Secretaría de Educación. Esos son motivos fuertes para haber pensado en la creación de la librería. Así, se busca revertir el apoyo en la editorial $\mathrm{y}$, además, recibir nuevos patrocinios sin restar que ellos también los gestionan.

\section{Conclusiones}

1 estudio de caso de la Editorial La Serpiente Emplumada permite ver que Ces una empresa que le apuesta a un sector como lo es la industria editorial, sabiendo de antemano que su cadena de valor es una de las más afectadas en las industrias culturales, puesto que Colombia es un país en el que no se presentan sólidos hábitos de lectura. Actualmente, el Ministerio de Cultura lidera en relación con la industria editorial la iniciativa denominada Leer es mi cuento, del Plan Nacional de Lectura y Escritura, por medio del cual incentiva el interés en el sector, estimulando la formulación de proyectos a través de estímulos. Así es como se reciben aproximadamente doscientos proyectos de Bogotá y veintiséis de otros departamentos del país, según lo informa su página web, con el ánimo de potencializar los hábitos de lectura, con diversas actividades de gestión cultural y bajo aspectos de inclusión, teniendo en cuenta que la iniciativa va dirigida a todo tipo de personas que puedan leer, incluso aquellas que sufran de discapacidad (Ministerio de Cultura, 2016). 
Por su parte, la Editorial La Serpiente Emplumada, en cabeza de su gerente Carmen Cecilia Suárez, presenta una buena gestión. Cabe mencionar que para ella la editorial, más que ser una empresa cultural, es un proyecto cultural en constante dinamismo y evolución. Es pertinente citar este comentario, pues permite apreciar que es justamente ese sentimiento de apropiación el que inhabilita en buena parte de los casos delegar funciones.

Este factor es de cuidado, pues independiente de que a la fecha se ha efectuado una innovadora gestión para procurar el sostenimiento de la empresa, la editorial se ha convertido con el tiempo justamente en eso, una empresa cultural, que, de faltar la gerente, debe procurar su sostenimiento desde un punto de vista empresarial.

El balance de gestión provisto por la gerencia para nutrir la investigación permite ver que hay una planeación estratégica dentro de la editorial con el propósito de perseguir su rentabilidad. El informe menciona que la editorial ha ganado prestigio por la calidad de sus publicaciones, tanto desde el punto de vista literario como académico y gráfico. Además, en 2010, se aumentó el ingreso por concepto de nuevas ediciones pasando de $\$ 14000000$ en 2009 a \$22 536963 en 2010. La presentación de los productos de consumo cultural, a saber, los libros, cuenta con buenos niveles de calidad que cautivan a públicos y escritores nuevos, nacionales e internacionales, que se quieren sumar a la cuota con que cuenta la editorial.

Es de analizar si los temas de distribución en contraste con las ventas en librerías se redujeron. Sin embargo, y para encontrar soluciones a problemas como estos, la editorial diseñó una venta de bodega, efectuada en abril de 2010 en la Fundación Gilberto Alzate Avendaño. Dicha iniciativa, y en contraste con diseños enmarcados en la gestión cultural, condujo al equipo de la editorial a repensar la necesidad de nuevas estrategias aliadas a la venta de libros, por ejemplo la firma de libros, la presentación de escritores y otro tipo de actividades culturales a fin de incrementar las ventas.

Otra de las respuestas a la pregunta que originó el planteamiento del problema de esta investigación, “¿Qué características ha presentado la Editorial La Serpiente Emplumada como modelo de gestión y como ejemplo de industria cultural y de qué manera ha desarrollado el trabajo en red?", son las nuevas 
propuestas que, desde la gestión cultural, ha diseñado la editorial con el ánimo de perseguir más sostenibilidad para su empresa. Dentro de estas cabe mencionar la celebración del primer decenio de la editorial, la edición digital, la comercialización de derechos de autor en otros países, la creación de la librería y la venta ambulante de libros en espacios como Parque de la 93, Parque Nacional y universidades, con el deseo de buscar nuevos mercados. 


\section{Referencias}

Alonso, G., Bonet, L., Garzón, A. y Schargorodscky, H. (2010). Políticas para la creatividad. Guía para el desarrollo de las industrias culturales y creativas. París: Unesco.

Cámara colombiana del libro. (2011). Comportamiento de la industria editorial. Recuperado de http://www.camlibro.com.co/Documentos \%202011/Estad \%C3 \%ADsticas \%20sector \%20editorial \%202007-2009.pdf

Cámara colombiana del libro. (2015). Estadísticas Sector Editorial en Colombia. Estadísticas del Libro en Colombia año 2015. Recuperado de http:/camlibro.com.co/historico-informes/

Colombo, A. y Roselló, D. (eds.) (2008). Gestión cultural: estudios de caso. Barcelona: Ariel.

Departamento Administrativo Nacional de Estadística DANE. (2008). Encuesta de consumo cultural ECC 2008. Recuperado de https://formularios.dane. gov.co/Anda_4_1/index.php/catalog/107

Departamento Nacional de Planeación _ DNP. (26 abril 2010). Conpes 3659 de 2010. Política nacional para la promoción de las industrias culturales en Colombia.

Escobar,A.(1998).Lainvención deltercermundo: construccióny deconstrucción del desarrollo. Barcelona: Norma.

Escobar, A. (1999). El final del salvaje: naturaleza, cultura y politica en la antropología contemporánea. Bogotá: Cerec.

García Canclini, N. (1995).Consumidores y ciudadanos. México: Grijalbo.

García Canclini, N. y Moneta, C. (eds.) (1999). Las industrias culturales en la integración latinoamericana. Buenos Aires: Eudeba. 
García Canclini, N. y Piedras, E. (2006). Industrias culturales y desarrollo. México: Fondo de Cultura Económica.

Martín Barbero, J. (1998). De los medios a las mediaciones. Bogotá: Convenio Andrés Bello.

Martín Barbero, J. (2002). Tecnología: innovaciones sociales y usos culturales. En Oficio de cartógrafo (pp. 176-204). Santiago de Chile: Fondo de Cultura Económica.

Ministerio de Cultura (2016). ¿Qué es leer es mi cuento? Recuperado de http:// www.mincultura.gov.co/leer-es-mi-cuento/Paginas/leer-es-mi-cuento.aspx

Observatorio de Cultura y Economía. (2016). Observatorio de Cultura y Economía. Producción de libros y lectura en Iberoamérica. Recuperado de http://culturayeconomia.org/2017/05/08/la-produccion-de-libros-y-lalectura-en-iberoamerica/

Parrish, D. (s. f.). Una guía para los negocios creativos. Bogotá: Universidad Jorge Tadeo Lozano.

Piedras Feria, E. (2004).¿Cuánto vale la cultura? México: Consejo Nacional para la Cultura y las Artes

Pimentel, M. (2007). Manual de editor: cómo funciona la moderna industria editorial(2. ${ }^{\mathrm{a}}$ ed.).Barcelona: Berenice Manuales.

Puente, S. (2007). Industrias culturales. Buenos Aires: Prometeo.

Rey, G. (2010). Industrias culturales creatividad y desarrollo. Madrid: Agencia Española para la Cooperación Internacional y el Desarrollo. 
